\title{
Dynamic Accuracy Design Method of Ultra-precision Machine Tool
}

\author{
Guo-Da Chen ${ }^{1,2^{*}}$, Ya-Zhou Sun ${ }^{1}$, Fei-Hu Zhang ${ }^{1}$, Li-Hua Lu' ${ }^{1}$, Wan-Qun Chen ${ }^{1}$ and Nan Yu ${ }^{3}$
}

\begin{abstract}
Ultra-precision machine tool is the most important physical tool to machining the workpiece with the frequency domain error requirement, in the design process of which the dynamic accuracy design (DAD) is indispensable and the related research is rarely available. In light of above reasons, a DAD method of ultra-precision machine tool is proposed in this paper, which is based on the frequency domain error allocation. The basic procedure and enabling knowledge of the DAD method is introduced. The application case of DAD method in the ultra-precision flycutting machine tool for KDP crystal machining is described to show the procedure detailedly. In this case, the KDP workpiece surface has the requirements in four different spatial frequency bands, and the emphasis for this study is put on the middle-frequency band with the PSD specifications. The results of the application case basically show the feasibility of the proposed DAD method. The DAD method of ultra-precision machine tool can effectively minimize the technical risk and improve the machining reliability of the designed machine tool. This paper will play an important role in the design and manufacture of new ultra-precision machine tool.
\end{abstract}

Keywords: Dynamic accuracy design, Ultra-precision machine tool, Frequency domain, Error allocation

\section{Introduction}

Ultra-precision machining technology plays an increasingly important role in the future manufacturing field. The surface quality requirement of the machined parts becomes higher and higher, especially in some application fields such as the precision optics [1]. This high requirement is not only represented by the realization of ultra-low PV and RMS values of the conventional surface roughness error in the spatial domain, but reflected by the harsh control of surface errors in the full spatial frequency domain $[2,3]$. The manufacturing of this kind of ultra-precision parts still mainly rely on the Ultraprecision Machine Tool (UMT), and the majority of the machining type is error-copying machining, which brings the difficulty and challenge for the design and manufacture of the UMT.

Accuracy design is an important tool for predicting and control the error when design a machine, which has wide

\footnotetext{
*Correspondence: gchen@zjut.edu.cn

${ }^{1}$ Center for Precision Engineering, Harbin Institute of Technology, Harbin 150001, China

Full list of author information is available at the end of the article
}

application in designing the machine tool, robot and coordinate measuring machine [4]. Generally, accuracy design of a machine tool can predict the whole accuracy by synthesizing the influence of each error sources so as to judge if the design meets the required accuracy specifications. Therefore, reasonable accuracy design is beneficial for minimizing the risk and cost, and the optimal decision and selection in the machine tool design.

In the traditional design of the UMT, one can basically meet the design requirements only by the Static Accuracy Design (SAD), in which the machine component errors are considered as static errors or quasi-static errors and the values used in the design model and its optimization model focuses on the amplitude characteristics of the errors.

SAD method is quite popular in machine tool design for the past decades due to its convenience and practicability. Donaldson [5] in Lawrence Livermore National Laboratory (LLNL) firstly systematically used the static error allocation in developing the world-famous UPM (LODTM). The PV error was estimated for considering totally 11 error sources induced errors, and then the budgeted workpiece roughness was obtained. Dorndorf
Springer Open

(c) The Author(s) 2018. This article is distributed under the terms of the Creative Commons Attribution 4.0 International License (http://creativecommons.org/licenses/by/4.0/), which permits unrestricted use, distribution, and reproduction in any medium, provided you give appropriate credit to the original author(s) and the source, provide a link to the Creative Commons license, and indicate if changes were made. 
et al. [6] studied the optimal allocation of static machine error around the minimum cost, in which considering the probability characteristics of the errors. Brecher et al. [7] used the error allocation in the compact design of machine tools for providing the possibility to avoid, separate and compensate the machine errors. Uriarte et al. [8] made the overall error allocation for a micro-milling machine, mainly considering the collet angular deformation and tool deflection. Erkorkmaz et al. [9] carried out the error budget for the $X-Y$ stage of precision machine tool, where the geometrical error, dynamic error, servo error and thermal error were mainly regarded. Cheng et al. [10] employed the error allocation for the optimum selection of key motion components and its position accuracy allocation when designing a desktop multiaxis laser machine for micro tool fabrications. Lin and Ehmann [11] discussed the tolerance distribution among the links and joints of a multi-axis machine. The allowable error tolerance limits of the link parameters and of the error motion of the joints were obtained through the maximum allowable tolerances definition for the position and orientation of the tool in the workspace. Huang and Zhang [12] studied the accuracy design of a gear hobber with complex forming motion based on the error prediction. Kang and Fan [13] studied the manufacturing accuracy allocation and optimization method of a CNC machine tool. The geometric error model was built by multi-body system theory, where the errors of angular displacement and perpendicularity were represented by the linear displacement errors. Yu et al. [14] conducted the accuracy distribution for a large CNC gantry guideway grinder based on the reliability theory, in which the reliability model is approximately established by response surface method with error samples from 25 sets of position of the grinder working stroke. Ding et al. [15] used similar method as above to study the accuracy design of the multi-axis machine tool oriented to remanufacturing. However, in the accuracy design process of the UPM, the linear errors and angular errors should be independently treated for its higher accuracy target than common machine tools. For solving this problem, and also for lessening the dependence on the engineering experience and improving the methodological portability, a new static accuracy design method of UPM based on global optimization and error sensitivity analysis was presented by Chen et al. [16]. In this method, the problem of static error allocation of the machine tool was transformed to that of multi-objective optimization with nonlinear constraints. The objective functions simultaneously consider the optimization of cost, balance and robustness. And, the sensitivity analysis was used in the stages of optimization and post-optimization respectively. Certainly, many studies about SAD method in the field of parallel mechanism and machine tool are also available, such as Song et al. [17] and Ni et al. [18], in which the common steps of error modeling, sensitivity analysis and optimization are also included.

Although the SAD method has lots of application in machine tool design, it is quite difficult and even impossible to be used in the machine tool for machining the workpieces with the requirement of frequency domain errors as mentioned above. In that case, the frequency contents of the dynamic errors must be considered in the design process, i.e., the accuracy or error to be allocated or budgeted is frequency dependent. The accuracy design method considering the frequency domain errors characteristics is rarely discussed, the related research of which is also far from enough.

For satisfying the workpiece machining with the requirement of frequency domain errors, in this paper, we propose a Dynamic Accuracy Design (DAD) method of UPM. In Section 2, the basic principle of DAD method will be described. Then in Section 3, an application case about ultra-precision flycutting machine tool will be presented in detail. Consequently, the discussions are given in Section 4, followed by the conclusions.

\section{Basic Principle of DAD Method}

The DAD method of UPM is realized based on the frequency domain error allocation. Thus, the DAD process can also be considered as the allocation process of frequency domain error. The frequency domain errors are complex and difficult to foresee, and its influence factors contain the machining process parameters besides the dynamic errors of machine tool itself. Therefore, the proposed DAD method need rely on the previous data and experience to some extent, which is quite similar as that of SAD method. In the DAD process, the required frequency information or ${ }^{\circ}$ contents of the machine motion components still need to be obtained through the previous measurement data or the prediction by simulation.

The basic procedure of DAD method of UPM is shown as Figure 1. When the workpiece material and machined surface error specification is known, the conceptual design of the machine tool is firstly carried out, in which the component parts and structural layout is determined. The accuracy design starts after the conceptual design stage. Different from the SAD process, the process parameters such as spindle rotation speed, feed rate and cutting depth should be roughly determined based on the experience before DAD. The former two parameters, especially, have important influence on the frequency characteristics of the machined surface in the ultra-precision machining, which has been detailedly clarified by Chen et al. [19, 20]. 


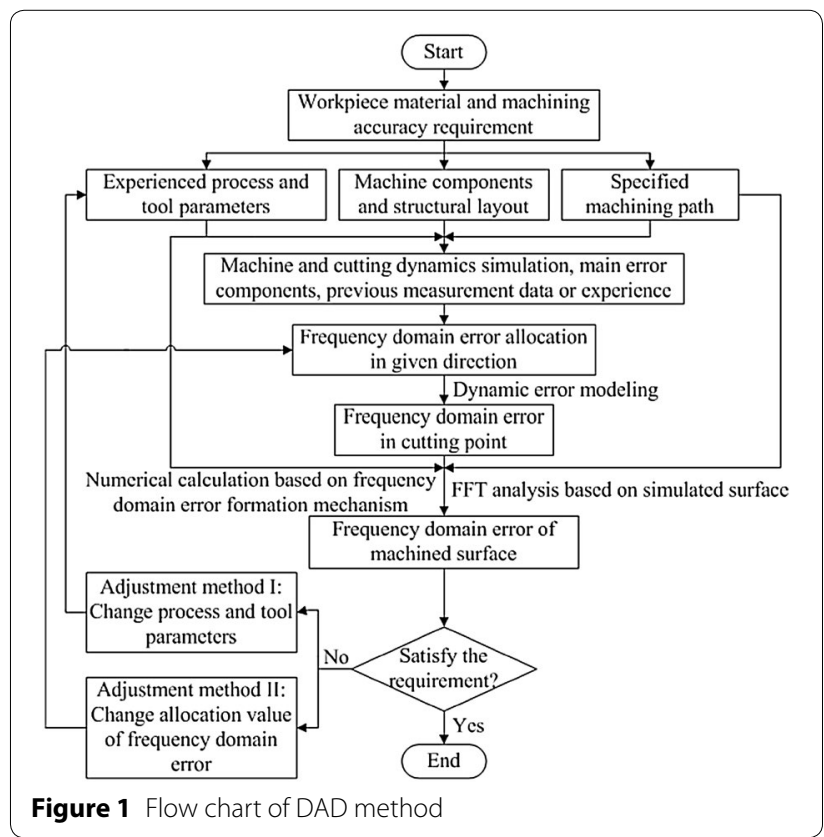

In the actual machining, cutting depth as a key parameter of cutting dynamics, therefore, has certain influence on the vibration errors. In addition, the machining path or tool motion trajectory should also be preliminarily decided prior to the DAD. When the above-mentioned conditions and parameters are known, one can basically acquire the main error components or errors that mostly affect the machining accuracy. Then, the tool-work relative vibration errors, i.e., the vibration errors needed for the dynamic error modeling [21], which can be obtained by the machine and cutting dynamics simulation. Due to the relatively complexity of the DAD, pre-measured data or experience is also needed. For example, the research group of machine tool development has plenty of experience in manufacturing and measurement of spindle and guideway errors, and masters some rules of these errors, which is quite useful. In the actual process of frequency domain error allocation, the errors are difficult to measure prior to the completion of the machine tool manufacture. Thus, one can only try to get the frequency and amplitude information of each error by the simulation method or the experience.

When the predicted values (frequency and amplitude) of the main errors are obtained, the frequency domain error allocation can be made, usually only for the machining sensitive direction. Then, the frequency domain errors can be gained according to the dynamic error modeling method introduced in Ref. [21]. For the UPM design with the simpler configuration, the above step can be omitted due to its low error coupling between the motion axes. In this case, the predicted frequency and amplitude information of the main errors can be directly regarded as the frequency domain errors in the cutting point. Generally, the frequency domain errors of machined surface can be obtained by certain methods if the frequency domain errors in the cutting point are known. One is the frequency domain error formation mechanism introduced in Refs. [19, 20], through which the spatial frequency components of the surface profile in the given direction can be calculated. For this method, the corresponding amplitude contents are hard to get. The other is FFT analysis based on the 3D surface formation simulation, by which the complete information of the frequency domain errors of the machined surface.

The requirement of frequency domain error is generally reflected in several specified frequency bands, and the requirement in each band is different. Let the obtained frequency domain errors of the machined surface be analyzed by the different bands, then judge if they meet the requirement or not according to the requirement in different bands. If yes, it indicates the allocation of frequency domain errors is reasonable. If not, there are two adjustment methods can be used, i.e., change the process and tool parameters or change the allocation values of frequency domain errors. The essence of the above two adjustment methods is change the frequency and amplitude contents of frequency domain errors of the machined surface in favorable direction through the change of the above parameters. By the former adjustment method, one can obtain a relatively easy target by transferring the frequency bands for the evaluation. For instance, if a targeted amplitude value in an evaluation frequency band is hard to realize, one can avoid this evaluation frequency band and transfer it to an evaluation frequency band for which the targeted amplitude value can be easily realized. In the field of ultra-precision machining, its accuracy target is quite high, thus, the above method is very meaningful. While, for the latter adjustment method, one need change the allocated values in the given frequency band directly (i.e., usually reduce the targeted amplitude value), which will increase the task difficulty. Anyway, the above two adjustment methods are both feasible. Finally, the allocated values of frequency domain errors will provide the theoretical reference for the actual manufacture and assembly of machine tool components.

\section{Application of DAD Method in Ultra-precision Flycutting Machine Tool}

The DAD method can be applied in many different kinds of UPMs. In this research, we give a DAD example of KDP crystal ultra-precision machine tool to show the specific description of implementation steps of DAD method. 


\subsection{Machining Target Specifications and Machine Tool Structure}

The KDP crystal is one of the nonlinear optical materials with high laser-damaged threshold, the large aperture optical component made of which is the only frequency converter and electro-optic switch component that adopted in high power laser driver system of Inertial Confinement Fusion (ICF) [22]. However, KDP crystal is also one of the famously most difficult-to-cut materials. It has the characteristics of anisotropy, soft, fragile, easy cracking and deliquescence, which needs the final machining to be finished by ultra-precision single point diamond flycutting [2]. The KDP crystal has harsh requirements of frequency domain errors, because its low, middle and high frequency wavefront distortion errors all have important influence on the quality of the laser beam. Therefore, the frequency domain errors in the KDP machining must be controlled. Table 1 lists the specifications for KDP crystal machining in ICF [23]. GRMS, Rq, pk, avg and PSD represent RMS gradient, RMS roughness, peak value, mean value and power spectral density, respectively.

It can be seen from Table 1 that the errors in low-frequency band need meet the GRMS specification. The errors in middle-frequency band not only need satisfy the RMS roughness requirement, but also the frequency domain error requirement that evaluated by PSD. And, the errors in high-frequency band need satisfy the RMS roughness requirement. The PSD evaluation function adopts the formula that given seen in ISO10110-8 [24], in which the related parameter values refer to the empirical data of LLNL as shown in Eq. (1):

$$
P A=15 f_{P S}^{-1.55}
$$

where $f_{P S}$ is the spatial frequency of the evaluated surface profile $\left(\mathrm{mm}^{-1}\right)$.

According to the machining requirement of large aperture KDP crystal, the overall structural layout of ultra-precision flycutting machine tool is determined, as shown in Figure 2. It is vertical configuration with short kinematic chain, compact structural loop and high rigidity. The machine tool adopts aerostatic spindle and hydrostatic guideway. Traditional design of

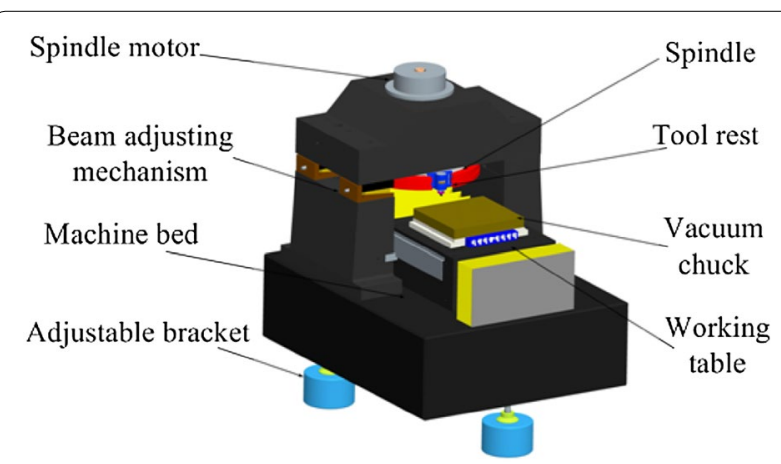

Figure 2 Structural layout of ultra-precision flycutting machine tool

ultra-precision flycutting machine tool fails to consider the requirement of frequency domain error of workpiece surface, so it has insufficient reliability to satisfy the frequency domain error requirement, although it meets the need of RMS roughness requirement. Thus, the DAD of ultra-precision flycutting machine tool for KDP machining is quite necessary, and the key point is to meet the frequency domain error requirement, which mainly refers to the PSD requirement in this case.

\subsection{Frequency Domain Error Allocation}

According to the specifications shown in Table 1, the workpiece only has the PSD requirement in middle-frequency band (i.e., Band 1 and Band 2). Considering that the RMS roughness requirement can be relatively easy to achieve by current technology, therefore, there are two strategies can be used when the predicted spatial frequency contents induced by the machine tool errors are in the middle-frequency band. One is to change the spatial frequencies to avoid the evaluation range of the middle-frequency band and enter in the evaluation range of other bands, making it easy to meet the corresponding requirements. The other is to reduce the amplitudes of the machine tool errors that resulted in the machined surface errors in the middle-frequency band, for meeting the PSD requirements.

The schematic diagram of ultra-precision flycutting and its machined surface is shown in Figure 3 [20], which

Table 1 Specifications for KDP crystal machining

\begin{tabular}{|c|c|c|c|c|}
\hline Measured band & Band 1 & Band 2 & Band 3 & Band 4 \\
\hline Spatial frequency $\left(\mathrm{mm}^{-1}\right)$ & $0.0025-0.03$ & $0.03-0.4$ & $0.4-8.3$ & $8.3-100$ \\
\hline Spatial period (mm) & $400-33$ & $33-2.5$ & $2.5-0.12$ & $0.12-0.01$ \\
\hline Parameter index I & $\begin{array}{l}\text { GRMS / }\left(\mathrm{nm} \cdot \mathrm{cm}^{-1}\right) \\
11\end{array}$ & $\begin{array}{l}\mathrm{Rq} / \mathrm{nm} \\
5\end{array}$ & $\begin{array}{l}\mathrm{Rq} / \mathrm{nm} \\
2.6 \mathrm{pk}, 1.5 \mathrm{avg}\end{array}$ & $\begin{array}{l}\mathrm{Rq} / \mathrm{nm} \\
2.5 \mathrm{pk}, 1.5 \mathrm{avg}\end{array}$ \\
\hline Parameter index II & None & $\begin{array}{l}\mathrm{PSD} /\left(\mathrm{nm}^{2} \cdot \mathrm{mm}\right) \\
\mathrm{PA}\end{array}$ & $\begin{array}{l}\mathrm{PSD} /\left(\mathrm{nm}^{2} \cdot \mathrm{mm}\right) \\
P A\end{array}$ & None \\
\hline
\end{tabular}




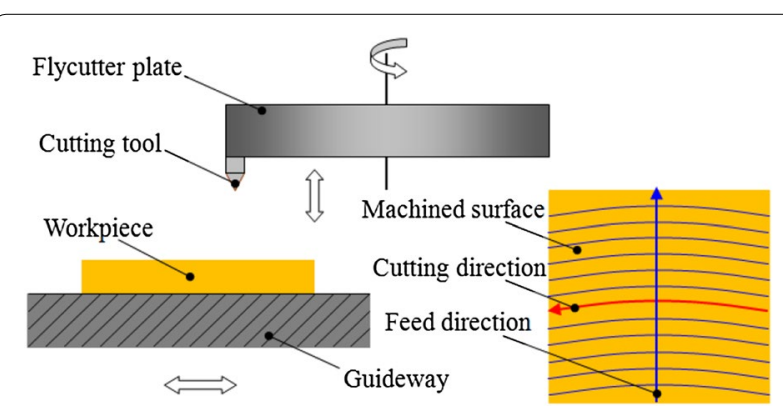

Figure 3 Schematic diagram of ultra-precision flycutting and its machined surface

shows the tool trajectory is actually determined by the spindle rotation angle [20]. The experienced process and tool parameters can be preliminarily set as follows: spindle rotation speed of $390 \mathrm{r} / \mathrm{min}$, feed rate of $0.06 \mathrm{~mm} / \mathrm{s}$, cutting depth of $5 \mu \mathrm{m}$, arc cutting edge of diamond tool, rake angle of $-25^{\circ}$, clearance angle of $8^{\circ}$, tool nose radius of $5 \mathrm{~mm}$.

Since KDP crystal is soft and the machine tool has high rigidity, the cutting depth of a few microns level has little impact on the amplitude of machine vibration, and basically has no effect on the frequency of machine vibration. Therefore, the DAD process does not put emphasis on the influence of cutting depth on the frequency domain errors of machine surface. Besides, due to the simple structure of ultra-precision flycutting machine tool, the dynamic error modeling is not needed in the DAD process, and the main error components can be directly turned into the errors in the cutting point. The main error components of the machine tool are the spindle errors, motion errors of working table (linear motion axes) and vibration errors, respectively. The above errors are the key errors in the DAD process, in which only the errors in the sensitive direction will be considered, i.e., the errors in $Z$ direction in this case.

For the spindle errors, only the asynchronous errors affect the spatial frequencies in the feed direction, and the synchronous errors has no effect on the spatial frequencies in that direction [20]. When the spindle rotation speed is $390 \mathrm{r} / \mathrm{min}$, only the spindle errors with the frequency value over $56.8 \mathrm{~Hz}$ possibly influence the spatial frequencies in the cutting direction. Consequently, the low-frequency errors with the frequency value less than the fundamental frequency (i.e., $6.5 \mathrm{~Hz}$ ) has no effect on the spatial frequencies of the machined surface in the cutting direction. Besides, if only considering the low-frequency errors in this range, when the feed rate is $0.06 \mathrm{~mm} / \mathrm{s}$, the frequencies of corresponding low-frequency errors for $8.3 \mathrm{~mm}^{-1}$ and $0.03 \mathrm{~mm}^{-1}$ are $0.498 \mathrm{~Hz}$ and $0.0018 \mathrm{~Hz}$, respectively. When the frequency of low-frequency error is larger than $0.498 \mathrm{~Hz}$, the corresponding spatial frequency in the feed direction will enter into Band 4, which does not influence the PSD specification. Therefore, for the error with the frequency value in the range of less than the fundamental frequency, the frequency of low-frequency error needs to be larger than $0.498 \mathrm{~Hz}$.

For the spindle error with the frequency value larger than the fundamental frequency, the spatial frequencies of the machined surface in the cutting direction induced by the synchronous and asynchronous errors of the spindle can be calculated by Eq. (2):

$$
f_{\mathrm{cd}}=\frac{30 f_{\mathrm{e}}}{\pi r_{\mathrm{TR}} n_{\mathrm{s}}}
$$

where $f_{\mathrm{cd}}$ is the spatial frequency of the machined surface in the cutting direction $\left(\mathrm{mm}^{-1}\right), r_{\mathrm{TR}}$ is the rotation radius of the cutting tool tip $(\mathrm{mm}), n_{\mathrm{s}}$ is the spindle rotation speed $(\mathrm{r} / \mathrm{min}), f_{\mathrm{e}}$ is the frequency of the spindle error $(\mathrm{Hz})$.

For the spatial frequencies in the feed direction, only the asynchronous errors of the spindle need to be considered. Its corresponding spatial frequency values can be calculated through the frequency domain error formation mechanism. For avoiding the evaluation range of PSD, it should be guaranteed that the time domain frequencies after the aliasing effect are larger than $0.498 \mathrm{~Hz}$.

According to the previous spindle error analysis [25], the main spindle errors contain the synchronous errors with the frequency values less than three-fold frequency and with the frequency value of 12 -fold frequency and 24-fold frequency, and a low frequency asynchronous error with $0.6 \mathrm{~Hz}$ induced by the air film vibration (the frequency value may has small change due to the change of air film status in different periods, but it does not have any influence on the analysis in this paper). When the spindle rotation speed is $390 \mathrm{r} / \mathrm{min}$, the time domain frequencies of the main synchronous errors are $6.5 \mathrm{~Hz}, 13 \mathrm{~Hz}, 77.5 \mathrm{~Hz}$ and $154.9 \mathrm{~Hz}$. However, as the synchronous errors, they do not have the influence on the spatial frequencies of machined surface in the feed direction. Moreover, in these four main synchronous errors, only the errors with the frequency of $77.5 \mathrm{~Hz}$ and $154.9 \mathrm{~Hz}$ have certain influence on the spatial frequencies of machined surface in the cutting direction. Because it is reflected in the circumferential direction, the corresponding spatial frequencies in the perpendicular direction of feed direction are difficult to measure. Nevertheless, as for its influence, it only has the influence on specifications in Band 1, not affecting the PSD specifications. The main asynchronous error $(0.6 \mathrm{~Hz})$ does not affect the spatial frequencies of machined surface in the cutting direction, but affects that in the feed 
direction. Combining the related process parameters, the corresponding spatial frequency can be calculated, i.e., $10 \mathrm{~mm}^{-1}$, which belongs to the evaluation range of Band 4. Thus, it need not satisfy the PSD requirement. To sum up, when the spindle rotation speed is $390 \mathrm{r} / \mathrm{min}$, the main spindle errors basically do not influence the frequency domain error specifications.

By the known process parameters, the feed frequency can also be obtained, i.e., $108.3 \mathrm{~mm}^{-1}$. Thus, the possible main spatial frequency contents induced by the coupling effect of this frequency and the asynchronous error induced spatial frequency $\left(10 \mathrm{~mm}^{-1}\right)$ basically belong to high-frequency band, even may not in any frequency band shown in Table 1. It may have the spatial frequency that belong to Band 4, but apparently does not need satisfy the PSD requirement.

The motion error of the working table is mainly the vertical straightness error, which is low frequency error and mainly influences the figure accuracy. It belongs to the evaluation range of Band 1, thus, only need satisfy GRMS requirement. According to our measurement results, the vertical straightness error can be controlled at about $0.12 \mu \mathrm{m}$. Based on the previous research results [26], under the effect of this vertical straightness error, GRMS value can be controlled at $10 \mathrm{~nm} / \mathrm{cm}$, which can meet the requirement.

The vibration errors of ultra-precision flycutting machine tool for KDP crystal are mainly the vibration errors under internal and external incentives. For the vibration errors caused by the external environment, if without isolation platform, even the low frequency ground vibration can also cause high frequency vibration of cutting tool, but if the machine tool has vibration isolation platform, it is not easy to generate such errors. In this case, the vibration isolation platform is used acquiescently, so this kind of vibration errors will not be considered in the DAD process. For the vibration errors caused by the internal structure, we mainly consider the Natural Vibration Induced Errors (NVIE) and the Oil Pressure Fluctuations Induced Errors (OPFIE) in the hydraulic system.

For the NVIE, the main frequencies are natural frequencies, in which the first few order natural frequencies have relatively large impact. Generally, the first six order natural frequencies of ultra-precision flycutting machine tool are between $100 \mathrm{~Hz}$ and $600 \mathrm{~Hz}$. Through Eq. (2), the corresponding spatial frequency of machined surface in the cutting direction of $100 \mathrm{~Hz}$ and $600 \mathrm{~Hz}$ can be calculated, i.e., $0.0078 \mathrm{~mm}^{-1}$ and $0.0467 \mathrm{~mm}^{-1}$, respectively. If the spatial frequencies of machined surface in the cutting direction do not enter into the evaluation range of middle-frequency range, the values of natural frequencies must be less than $385 \mathrm{~Hz}$, for which the corresponding spatial frequencies belong to the evaluation range of Band 1 and need not satisfy the PSD specification. From the viewpoint of actual engineering, it can be fully achieved to make the first few order natural frequencies (taking the first six order natural frequencies as the example) less than $385 \mathrm{~Hz}$ [3]. It can be controlled in the machine design stage, and can also be realized by adjusting the rigidity of the existing machine tool. The influence of NVIE on the spatial frequency of machined surface in the feed direction can be analyzed by the frequency domain error formation mechanism. The values of natural frequencies can be obtained through the machine dynamics simulation and previous measurement. However, according to the previous measurement experience, the spatial frequencies of machined surface in the feed direction are basically the high frequency errors, i.e., belong to the evaluation range of Band 4. Thus, we do not have to consider the influence of NVIE on the spatial frequency of machined surface in the feed direction.

For the OPFIE, it is previously found that caused the micro-displacement of the working table in $Z$ direction, which will influence the spatial frequencies in the feed direction. The time period of OPFIE is about 10-30 $\mathrm{s}$, so the corresponding time domain frequencies are $0.033-0.1 \mathrm{~Hz}$. They are low frequency errors, and the corresponding spatial frequencies in the feed direction are $0.55-1.67 \mathrm{~mm}^{-1}$, which belong to the evaluation range of Band 3 and need satisfy the PSD requirement. If making it away from the evaluation range of middle-frequency band, the feed rate must be larger than $3.33 \mathrm{~mm} / \mathrm{s}$ or be less than $0.0039 \mathrm{~mm} / \mathrm{s}$, then, it enters into the evaluation range of Band 1 or Band 4, respectively. However, both of the above two solutions are not feasible. The former one is easy to affect the machining quality, and the latter one affects the machining efficiency. Moreover, adjusting the feed rate will lead to the change of spatial frequencies induced by the other kinds of errors, which is not conducive to the DAD. If the OPFIE is inevitable, we need combine the PSD specification to control its amplitude. Considering the nonlinearity of oil pressure fluctuation and the response delay characteristics, the allocated amplitude value of OPFIE is set as $10 \mathrm{~nm}$.

In summary, for the ultra-precision flycutting machine tool for KDP crystal, possible error sources leading to the spatial frequency contents in the middle-frequency band are mainly the spindle errors, NVIE and OPFIE. Under the process parameters with the spindle rotation speed of $390 \mathrm{r} / \mathrm{min}$ and the feed rate of $0.06 \mathrm{~mm} / \mathrm{s}$, however, one can make the spatial frequencies induced by the main spindle errors and NVIE avoid the evaluation range of middle-frequency band (i.e., enter into the evaluation range of low-frequency band or high-frequency band), eliminating the need to meet the PSD requirement. As 
for the OPFIE, if it can not be removed, we need control its amplitude to a certain level.

Based on the above analysis and the given process parameters, the main allocated error of the machine tool are listed as follows: the vertical straightness error with the amplitude less than of $0.12 \mu \mathrm{m}$, the spindle axial error with the amplitude less than of $60 \mathrm{~nm}$ and with the frequency larger than $0.5 \mathrm{~Hz}$ for the case of the frequency value less than the fundamental frequency (or with the aliased frequency larger than $0.5 \mathrm{~Hz}$ for the case of the frequency value larger than the fundamental frequency), the NVIE with the amplitude less than $40 \mathrm{~nm}$ and with the first six order natural frequencies less than $385 \mathrm{~Hz}$, the OPFIE with the amplitude less than $10 \mathrm{~nm}$ (when its vibration frequencies are between $0.033 \mathrm{~Hz}$ and $0.1 \mathrm{~Hz}$ ).

\subsection{Designed Ultra-precision Flycutting Machine Tool for KDP Crystal Machining Based on DAD Method}

Based on the DAD method and above error allocation data, the ultra-precision flycutting machine tool for KDP crystal machining is designed and manufactured, as shown in Figure 4. The main technical parameters of this machine tool are shown as follows: the vertical straightness error has the amplitude of $0.105 \mu \mathrm{m}$, the repeated positioning accuracy is $41 \mathrm{~nm}$, the spindle axial stiffness is $1219 \mathrm{~N} / \mu \mathrm{m}$, the spindle axial error has the amplitude of $35 \mathrm{~nm}$ and the frequency larger than $0.5 \mathrm{~Hz}$ for the case of the frequency value less than the fundamental frequency, the NVIE has the amplitude less than $40 \mathrm{~nm}$ and the first six order natural frequencies less than $380 \mathrm{~Hz}$, and the OPFIE has the amplitude of $6.5 \mathrm{~nm}$ and its vibration frequencies are between $0.033 \mathrm{~Hz}$ and $0.1 \mathrm{~Hz}$. All the parameter values meet the corresponding requirements of DAD results.

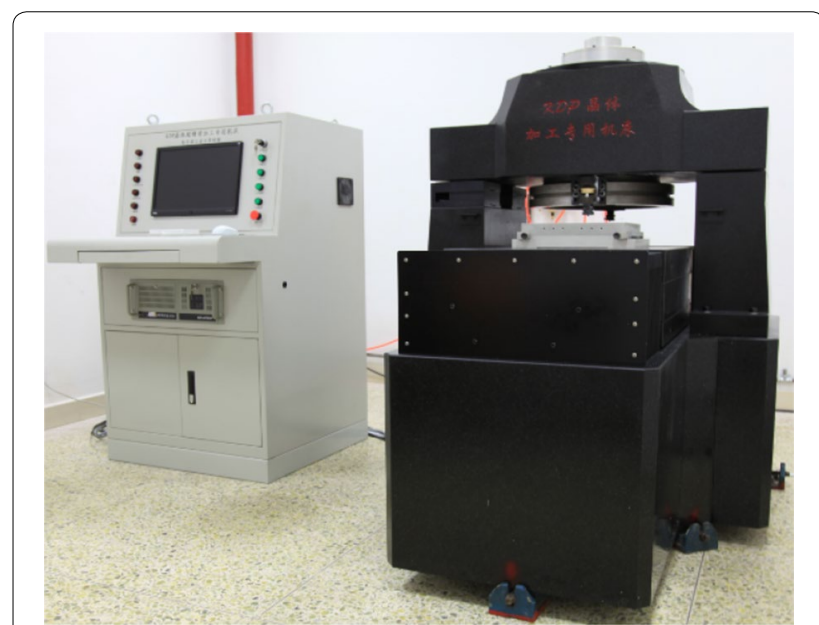

Figure 4 Ultra-precision flycutting machine tool for KDP crystal machining
The designed machine tool has good machining effect for KDP crystal. For the KDP crystal with workpiece size of $430 \mathrm{~mm} \times 430 \mathrm{~mm}$, the test results shows the machining quality can basically meet the specifications for KDP crystal as shown in Table 1. The designed ultra-precision flycutting machine tools have successful application in the SG-III Project of China.

\section{Discussions}

The accuracy design method is usually used in the design stage of the machine tool. Nevertheless, it should be noted that DAD is not always used before the manufacturing of machine components. It can also be used in the period that the motion components have been manufactured but the final assembly is not carried out yet, because in the design stage, the frequency domain errors are relatively difficult to estimate, therefore, one can only obtain the results of frequency domain error allocation under some certain frequency domain ranges by the DAD method. However, one can measure the errors of motion components then for better understanding its frequency domain errors, which can enhance the effectiveness of the DAD results. Furthermore, the accuracy adjustment of each single motion component before the final assembly is much more convenient and flexible than that after the final assembly. And, the frequency information is not necessarily a specific value, but generally a certain interval or a set of regular values. If the former, each interval boundary values will be used in the subsequent process, so the DAD process often require multiple numerical calculations or simulations.

The DAD process should pay attention to both the frequency and amplitude contents of the errors. However, it should be mentioned that the measured amplitude of the error with certain frequency does not directly correspond to the amplitude of its corresponding spatial frequency of the machined surface. For instance, the amplitude of the axial spindle errors are in the order of tens of nanometers, which does not mean the amplitudes of corresponding spatial frequencies of the machined surface are also in this order, because the machining process is quite complex and the influence of many other factors such as cutting damping also needs to be considered. In this paper, these factors are not considered, but will be studied in the future. Therefore, the effective prediction of the mentioned surface formation method in this study mainly aims at the surface spatial frequency rather than the amplitude.

However, considering that the specifications of roughness are relatively easy to realize currently, when the surface spatial frequencies induced influenced by the errors of a machine component are not located in the evaluation range of the middle-frequency band, the experience 
of machine tool development can be used to guide the accuracy allocation of this machine component.

In brief, the DAD method is very necessary to develop the ultra-precision machine tool for machining the workpiece with the frequency domain error requirement, for which the traditional accuracy design methods can hardly realize. It can minimize the technical risk, improve the machining reliability of the designed machine tool and reduce the cost. And, in the implementation process of this method, many factors should be considered and much technology needs to be relied on.

\section{Conclusions}

(1) For the ultra-precision machine tool for machining the workpiece with the frequency domain error requirement, the Dynamic Accuracy Design (DAD) is indispensable. A DAD method for the ultra-precision machine tool is proposed.

(2) The DAD method is based on the frequency domain error allocation, the implementation steps and enabling knowledge of which is introduced.

(3) The application case of DAD method in the ultraprecision flycutting machine tool for KDP crystal machining is described to show the procedure detailedly. In this case, the KDP workpiece has the requirements in four different spatial frequency bands, and the emphasis for this study is put on the middle-frequency band with the PSD specifications.

(4) The results of the application case basically show the feasibility of the proposed DAD method. The advanced measurement technology and manufacturing related engineering experience is necessary for the successful implementation of this method.

\section{Authors' contributions}

GDC conceived and designed the study; YZS, FHZ, LHL, WQC and NY participated in the machine design and application verification for the proposed method. GDC wrote the manuscript. GDC and YZS critically revised the manuscript. All authors read and approved the final manuscript.

\section{Author details}

${ }^{1}$ Center for Precision Engineering, Harbin Institute of Technology, Harbin 150001 , China. ${ }^{2}$ Key Laboratory of E\&M, Ministry of Education \& Zhejiang Province, Zhejiang University of Technology, Hangzhou 310032, China. ${ }^{3}$ Precision Engineering Institute, Cranfield University, Bedford MK430AL, UK.

\section{Authors' Information}

Guo-Da Chen, born in 1986, is currently a lecturer at Key Laboratory of Special Purpose Equipment and Advanced Machining Technology of Ministry of Education, Zhejiang University of Technology, China. He received his PhD degree from Harbin Institute of Technology, China, in 2015. His research interests include ultra-precision machine tool and machining technology.

Ya-Zhou Sun, born in 1968, is currently a professor at Center for Precision Engineering, Harbin Institute of Technology, China. He received his PhD degree from Harbin Institute of Technology, China, in 2005. His research interests include ultra-precision machine tool and machining technology.

Fei-Hu Zhang, born in 1964, is currently a professor at Center for Precision Engineering, Harbin Institute of Technology, China. He received his PhD degree from Harbin Institute of Technology, China, in 1993. His research interests include ultra-precision machine tool and machining technology.
Li-Hua Lu, born in 1977, is currently a professor at Center for Precision Engineering, Harbin Institute of Technology, China. He received his PhD degree from Harbin Institute of Technology, China, in 2007. His research interests include ultra-precision machine tool and machining technology.

Wan-Qun Chen, born in 1987, is currently an associate professor at Center for Precision Engineering, Harbin Institute of Technology, China. He received his $\mathrm{PhD}$ degree from Harbin Institute of Technology, China, in 2014. His research interests include ultra-precision machine tool and machining technology.

Nan Yu, born in 1987, is currently a PhD candidate at Precision Engineering Institute, Cranfield University, UK. He received his Master degree from Harbin Institute of Technology, China, in 2013. His research interests include optical fabrication, nano-machining, plasma figuring and simulation.

\section{Acknowledgements}

Supported by Zhejiang Provincial Natural Science Foundation of China (Grant No. LQ16E050012), National Natural Science Foundation of China (Grant Nos. 51705462 and 51275115), and International Science and Technology Cooperation Program of China (Grant No. 2015DFA70630).

\section{Ethics approval and consent to participate}

Not applicable.

\section{Competing interests}

The authors declare that they have no competing interests

\section{Publisher's Note}

Springer Nature remains neutral with regard to jurisdictional claims in published maps and institutional affiliations.

Received: 30 August 2016 Accepted: 14 January 2018

Published online: 28 February 2018

\section{References}

1. M L Spaeth, K R Manes, C C Widmayer, et al. National Ignition Facility wavefront requirements and optical architecture. Optical Engineering, 2004, 43(12): 2854-2865.

2. YC Liang, $W \mathrm{Q}$ Chen, $Y Z$ S Sun, et al. Dynamic design approach of an ultra-precision machine tool used for optical parts machining. Proceedings of the Institution of Mechanical Engineers, Part B: Journal of Engineering Manufacture, 2012, 226 (11): 1930-1936.

3. Y C Liang, W Q Chen, Q S Bai, et al. Design and dynamic optimization of an ultraprecision diamond flycutting machine tool for large KDP crystal machining. The International Journal of Advanced Manufacturing Technology, 2013, 69(1-4): 237-244.

4. D Dornfeld, D E Lee. Precision manufacturing. New York: Springer-Verlag, 2008

5. R R Donaldson. "Error budgets" in technology of machine tools. Berkeley: Lawrence Livermore National Laboratory, 1980.

6. U Dorndorf, V S B Kiridena, P M Ferreira. Optimal budgeting of quasistatic machine tool errors. ASME Journal of Manufacturing Science and Engineering, 1994, 116(1): 42-53.

7. C Brecher, P Utsch, R Klar, et al. Compact design for high precision machine tools. International Journal of Machine Tools and Manufacture, 2010, 50(4): 328-334.

8. L Uriarte, A Herrero, M Zatarain, et al. Error budget and stiffness chain assessment in a micromilling machine equipped with tools less than 0.3 $\mathrm{mm}$ in diameter. Precision Engineering, 2007, 31: 1-12.

9. K Erkorkmaz, J M Gorniak, D J Gordon. Precision machine tool X-Y stage utilizing a planar air bearing arrangement. CIRP Annals - Manufacturing Technology, 2010, 59(1): 425-428

10. X Cheng, Y M Huang, S I Zhou, et al. Study on the generative design method and error budget of a novel desktop multi-axis laser machine for micro tool fabrications. The International Journal of Advanced Manufacturing Technology, 2012, 60(5-8): 545-552.

11. P D Lin, KF Ehmann. Inverse error analysis for multi-axis machines. ASME Journal of Manufacturing Science and Engineering, 1996, 118(1): 88-94. 
12. Q Huang, G B Zhang. Precision design for machine tool based on error prediction. Chinese Journal of Mechanical Engineering, 2013, 26(1): 151-157.

13. F Kang, J W Fan. A method for manufacturing accuracy distribution and optimization of a CNC machine tool. Mechanical Science and Technology, 2008, 27(5): 588-591. (in Chinese)

14. Z M Yu, Z J Liu, Y D Ai, et al. Geometric error model and precision distribution based on reliability theory for large CNC gantry guideway grinder. Journal of Mechanical Engineering, 2013, 49(17): 142-151. (in Chinese)

15. W Z Ding, M H Zhou, X D Huang, et al. Study on accuracy design of multiaxis machine tools oriented to remanufacturing. Journal of Basic Science and Engineering, 2007, 15(4): 559-568. (in Chinese)

16. G D Chen, Y Z Sun, L H Lu, et al. A new static accuracy design method for ultra-precision machine tool based on global optimisation and error sensitivity analysis. International Journal of Nanomanufacturing, 2016, 12(2): 167-180.

17. Y M Song, Y P Zhai, T Sun, et al. Interval analysis based accuracy design of a 3-DOF rotational parallel mechanism. Journal of Beijing University of Technology, 2015, 41(11): 1620-1626. (in Chinese)

18. Y B Ni, B Zhang, Y P Sun, et al. Accuracy analysis and design of A3 parallel spindle head. Chinese Journal of Mechanical Engineering, 2016, 29(2): 239-249.

19. G D Chen, Y C Liang, Y Z Sun. Frequency domain error analysis in turning. The International Journal of Advanced Manufacturing Technology, 2014, 73(5-8): 929-940.
20. G D Chen, Y Z Sun, F H Zhang, et al. Influence of ultra-precision flycutting spindle error on surface frequency domain error formation. The International Journal of Advanced Manufacturing Technology, 2017, 88(9-12): 3233-3241.

21. G D Chen, Y C Liang, K F Ehmann, et al. Fourier transform based dynamic error modeling method for ultra-precision machine tool. Proc. SPIE, 2014, 9281: 928102-1-9.

22. W Q Chen, L H Lu, Y C Liang, et al. Flatness improving method of KDP crystal in ICF system and its implementation in machine tool design. Proceedings of the Institution of Mechanical Engineers, Part E: Journal of Process Mechanical Engineering, 2015, 229(4): 327-332.

23. J H Campbell, R A Hawley-Fedder, C J Stolz, et al. NIF optical materials and fabrication technologies: an overview. Proc. SPIE, 2004, 5341: 84-101.

24. ISO 10110-8-2010, Optics and photonics — preparation of drawings for optical elements and systems, Part 8: Surface texture; roughness and waviness.

25. G D Chen, Y Z Sun, C H An, et al. Measurement and analysis for frequency domain error of ultra-precision spindle in a flycutting machine tool. Proceedings of the Institution of Mechanical Engineers, Part B: Journal of Engineering Manufacture, 2016, https://doi.org/10.1177/0954405416673102.

26. W Q Chen, Y C Liang, Y Z Sun, et al. Investigation on the influence of machine tool dynamics on the wavefront gradient of KDP crystals by flycutting. ASME Journal of Manufacturing Science and Engineering, 2014 136: 051006-1-6.

\section{Submit your manuscript to a SpringerOpen ${ }^{\odot}$ journal and benefit from:}

- Convenient online submission

- Rigorous peer review

- Open access: articles freely available online

- High visibility within the field

- Retaining the copyright to your article

Submit your next manuscript at $\boldsymbol{\nabla}$ springeropen.com 